\title{
Pregnant HIV Elite Control: Therapeutic Conduct?
}

\section{Marcela Agostini ${ }^{1,2 *}$, Carolina Sconochini ${ }^{3}$, Paula Maldacena ${ }^{3}$, Rocío Maldacena ${ }^{3}$, Maria Cristina Monaco ${ }^{3}$ and Magali Surra $^{3}$}

${ }^{1}$ Center of High Studies of Sciences in Human and Health Sciences, Rosario headquarters, Inter-American Open University (CAECIHS), Pellegrini 1618, Rosario, Santa Fe, Argentina

${ }^{2} \mathrm{CAICl}$ Institute, Mendoza 2612, Rosario, Santa Fe, Argentina

${ }^{3} \mathrm{CAECIHS}$, Headquarters Rosario, UAI

\begin{abstract}
HIV positive patients with sustained viral load $<50$ copies $/ \mathrm{mL}$ are defined as elite controls in the absence of antiretroviral therapy and normal CD4+ values. The occurrence of this type of infections in only 1 of every 300 people infected by HIV. Elite control patients (EC) account for 0.5 to $1 \%$ of all HIV-1 infected persons, who are able to control viral replication and maintain immune function over prolonged periods of time without antiretroviral therapy. The following situations have been postulated to understand the primary mechanism of viremia control: low susceptibility of CD4 cells to infection, infection with defective replication, viral control by the patient's immune system and low availability of CD4 cells susceptible to infection. Most data on viral control in elite controls suggest that HIV-specific CD8+ T cell responses are probably crucial in elite control. These can be conferred by the protective HLA alleles in some patients. Our objective is to communicate a rare case of daily presentation of external consultation in this pathology.
\end{abstract}

Keywords: HIV; Pregnancy; HCV

\section{Clinical Case}

A 34 year old female patient who consults for Elisa positive for HIV in routine pregnancy control during the 20th week of gestation. Western Blot is performed confirming the infection. A serodiscordant couple does not report intravenous drug use or transfusion. CD4+ and HIV viral load were requested, which yielded the following results: CD4+ 999 cell $/ \mathrm{mm}^{3}$, ND viral load (not detectable, Cobas Ampliprep/ Cobas Taqman HIV-1 Virus Test 2.0) [1].

\section{Physical exam}

Patient lucido oriented in time and space. Preserved vital signs,no alterations are observed.

\section{Complementary methods}

Anti-HIV serology on 3 samples, with two different enzyme-immunoassay techniques, Roche ( $r p=2320,2220)$, Abbot $(r p=587)$. Detectable proviral DNA. On a new sample, we repeat the viral load with ND result. We discard type 2 HIV infection using nucleic acid test for blood bank (Cobas Taqscreen MPX test, V2.0, Roche). Considering the possibility of mutations in the binding region of the primers of the quantification technique, we used a RT-PCR-NESTED protocol that amplifies protease and retro viral transcriptase, in which we did not obtain amplification product $[2,3]$.

On the other hand, we requested serology for HBV, HCV, Chagas, Toxoplasmosis and Syphilis, all negative.

Given the incongruity in the studies performed, we contacted the parent company of Roche in the USA, where an investigation is initiated yielding the following result: sequencing of the gag region with positive result, the sequence corresponds to a Wild type virus, and sequencing of the negative LTR region. They conclude that this is a wild virus, with low or no viral load, which in the absence of treatment, corresponds to a case of HIV elite control.

Antiretroviral therapy with zidovudine/lamivudine is started twice daily. The patient is monitored during the course of pregnancy; the ACTG 076 protocol is decided. The baby was born by vaginal delivery, with negative serology, is repeated at two months where it is again negative and again negative at three months. The baby was treated with zidovudine the first month of life [4].

\section{Discussion}

Vertical transmission remains the main form of infection for more than $90 \%$ of children who acquire this infection. However, in pregnant women receiving antiretroviral therapy, this transmission decreased to below $2 \%$. It can occur during pregnancy, during delivery or after delivery through breastfeeding $[5,6]$.

So far there is no guide with precise indications about handling in this situation. The ACTG 076 study demonstrated a $67 \%$ reduction in vertical transmission with zidovudine monotherapy [7].

Regarding the time of the beginning of the treatment, both national and European guidelines recommend its establishment as soon as possible and no later than the second trimester $[5,6]$. In our case the patient was 20 weeks and the beginning was at the time of diagnosis.

It was decided to start with the combination of zidovudine and lamivudine in order to reduce the risk of vertical transmission. In the literature we present a case of an HIV positive female elite control in Zimbabwe 15 weeks' gestation where zidovudine monotherapy was instituted following the guidance of the BHIVA guideline and was offered to the elective cesarean patient, with therapeutic success. Lactation was contraindicated [8].

Taylor et al. Mentions the ACTG 076 monotherapy with zidovudine

${ }^{*}$ Corresponding author: Marcela Agostini, Center of High Studies of Sciences in Human and Health Sciences, Rosario headquarters, Inter-American Open University (CAECIHS), Lecturer Semiology and Adjunct Professor of Interna Medicine I and II, Medicine Career, UAI, Pellegrini 1618, Rosario, Santa Fe, Argentina, Tel: 0341-4356510; E-mail: Marcela.Agostini@UAl.edu.ar

Received September 01, 2017; Accepted September 11, 2017; Published September 18, 2017

Citation: Agostini M, Sconochini C, Maldacena P, Maldacena R, Monaco MC, et al (2017) Pregnant HIV Elite Control: Therapeutic Conduct? J AIDS Clin Res 8: 727 doi: 10.4172/2155-6113.1000727

Copyright: (c) 2017 Agostini M, et al. This is an open-access article distributed under the terms of the Creative Commons Attribution License, which permits unrestricted use, distribution, and reproduction in any medium, provided the original author and source are credited. 
Citation: Agostini M, Sconochini C, Maldacena P, Maldacena R, Monaco MC, et al. (2017) Pregnant HIV Elite Control: Therapeutic Conduct? J AIDS Clin Res 8: 727. doi: 10.4172/2155-6113.1000727

where the rate of transmission if the viral load was $<1000$ copies $/ \mathrm{ml}$ of HIV RNA was $1 \%$. Treatment reduced transmission even among women with mild or undetectable HIV viral load, suggesting that the effects of treatment are not related to decrease maternal viremia, but may also be related to HIV reduction in the genital tract and/or the preexposure prophylaxis of the infant by placental transfer of zidovudine. The introduction of TAAE (zidovudine-lamivudine-abacavir) may provide greater tranquility in the prevention of vertical transmission, however, it will expose the mother and baby to greater toxicity [9].

\section{Conclusion}

The prevalence of HIV elite control is very low in the daily consultation and even more in the context of a pregnant patient. Antiretroviral therapy should be initiated and continued with the protocol for the benefit of the mother and the baby.

\section{References}

1. Olson AD, Meyer L, Prins M, Thiebaut R, Gurdasani D, et al. (2014) An evaluation of HIV elite controller definitions within a large seroconverter cohort collaboration. PLoS ONE 9: e86719.
2. Watters SA, Mlcochova P, Maldarelli F, Goonetilleke N, Pillay D, et al. (2016) Sequential CCR5-tropic HIV-1 reactivation from distinct cellular reservoirs following perturbation of elite control. PLOS ONE 11: e0158854.

3. Saag M, Deeks SG (2010) How do HIV elite controllers do what they do? Clin Infect Dis 51: 239-241.

4. Blankson JN (2010) Control of HIV-1 replication in elite suppressors. Discov Med 9: 261-266.

5. European AIDS Clinical Society (EACS) (2015) Guidelines for the clinical management and treatment of HIV infected adults in Europe.

6. Agostini M (2011) VIH y Embarazo En Zanuttini E Temas de Obstetricia Ascune, Buenos Aires, Argentina 281-292.

7. Connor EM, Sperling RS, Gelber R, Kiselev P, Scott G, et al. (1994) Reduction of maternal-infant transmission of human immunodeficiency virus type 1 with zidovudine treatment. N Engl J Med 331: 1173-1180.

8. Rutland E, Mani R (2010) Management of pregnancy in an HIV elite controller. Int J STD AIDS 21: 604-605.

9. Taylor GP, Clayden P, Dhar J, Gandhi K, Gilleece Y, et al. (2012) British HIV association guidelines for the management of HIV infection in pregnant women 2012. HIV Med 13: 87-157. 